\title{
THE ROLE OF Mg ON STRUCTURE AND MECHANICAL PROPPERTIES IN ALLOY 718
}

\author{
Xishan Xie, Zhichao Xu, Bo Qu and Guoliang Chen \\ University of Science and Technology, Beijing 100083, China \\ John F. Radavich, School of Materials Engineering \\ Purdue University, W. Lafayette, In 47906, USA
}

\begin{abstract}
The role of $\mathrm{Mg}$ in alloy 718 has been systematically investigated. $\mathrm{Mg}$ raises not only high temperature tensile and stress-rupture ductilities but also increases considerably smooth and notch stress-rupture life. Mg containing alloy $718 \mathrm{M}$ is free of stress-rupture notch sensitivity. $\mathrm{Mg}$ improves creep and fatigue interaction properties (LCF or cyclic stress rupture) at any grain size. The basic role of $\mathrm{Mg}$ is equilibrium segregation at grain boundaries which helps to change continuous grain boundary $\delta-\mathrm{Ni}_{3} \mathrm{Nb}$ morphology to discrete globular form which has a retardation effect on intergranular fracture. $\mathrm{Mg}$ promotes the change from intergranular to transgranular fracture mode.
\end{abstract}




\section{INTRODUCTION}

For the past several decades, alloy 718 continues to be used in gas turbines in greater volume and for many applications. High performance demands and high quality requirements expecially in disk application, have required material homogenity, grain size control, and high mechanical properties (such as LCF or cyclic stress rupture) at operating conditions.

In the early 70's Couts et al. [1] studied the effect of $\mathrm{Mg}$ (from 1-350 ppm) on mechanical properties of alloy 718 and showed stress rupture ductility improvement in the range of $\mathrm{Mg}$ content from 30 to $200 \mathrm{ppm}$, but little data was presented in the lower content range (up to $100 \mathrm{ppm}$ ) of $\mathrm{Mg}$. In 1971 Muzyka et al. [2] showed beneficial stress rupture ductility improvement at $30 \mathrm{ppm} \mathrm{Mg}$ in alloy 718 .

Recently, Moyer [3] in his extra low carbon alloy 718 study showed a remarkable stress rupture ductility and life improvement with a small addition of $\mathrm{Mg}$ (13-19 ppm). However, the true effects of $\mathrm{Mg}$ have not been fully understood. A systematic research study of $\mathrm{Mg}$ effect in nickel- and iron-base superalloys has been conducted in China for a long time [4]. Our previous studies $[5,6]$ show optimum small addition of $\mathrm{Mg}$ (less than $100 \mathrm{ppm}$ ) not only can increase stress rupture ducitlity but also prolong stress rupture life. The beneficial effect of $\mathrm{Mg}$ in alloy 718 can be still maintained even after $5000 \mathrm{hrs}$ long time exposure at $650^{\circ} \mathrm{C}$. For further understanding the role of $\mathrm{Mg}$ in wrought alloy 718 , especially for disk application, an investigation of $\mathrm{Mg}$ and grain size effects on structure and mechanical properties, especially on stress rupture notch sensitivity and cyclic stress rupture or LCF was undertaken.

\section{MATERIALS AND EXPERIMENTAL PROCEDURE}

Two $79 \mathrm{Kg}$ heats of alloy 718 containing $4 \mathrm{ppm}$ (mg free) and $59 \mathrm{ppm}(\mathrm{Mg}$ containing) were VIM melted. Chemical composition and alloy designation are listed in Table I.

Table I. Alloy Chemical Compositions (wt \%)

$\begin{array}{llllllllllllll}\text { Alloy } & \text { C } & \text { Mn } & \text { Si } & \text { P } & \text { S } & \text { Cr } & \text { Fe } & \text { Mo } & \text { Al } & \text { Ti } & \text { Nb } & \text { B } & \text { Mg } \\ 718 & 0.057 & 0.04 & 0.23 & 0.006 & 0.004 & 19.10 & 18.24 & 2.95 & 0.68 & 1.01 & 4.98 & 0.0054 & 0.0004 \\ 718 \mathrm{M} & 0.052 & 0.04 & 0.23 & 0.006 & 0.004 & 19.04 & 18.10 & 2.95 & 0.67 & 1.00 & 4.98 & 0.0058 & 0.0059\end{array}$

Alloy ingots were partially homogenized at $1150^{\circ} \mathrm{C}$ for 6 hours and then forged to produce different grain size experimental disks $(\phi 200 \times 45 \mathrm{~mm})$. Typical structure of coarse, fine and mixed grains are shown in Fig. 1.

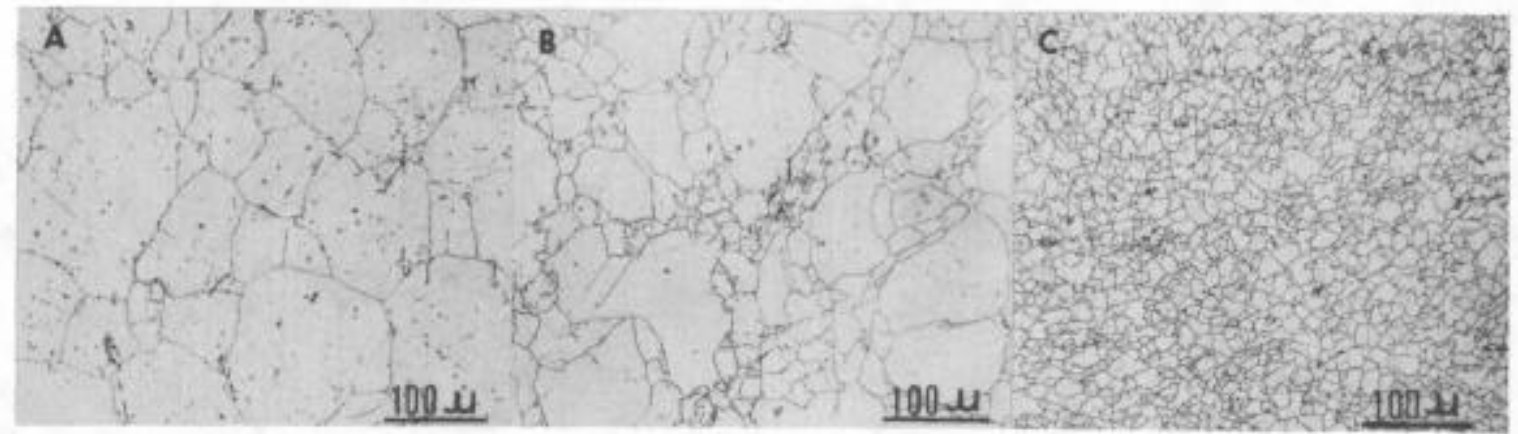

Fig. 1. Typical grain structure of experimental disks with different ASTM grain sizes (after heat treatment); (A) coarse grain, (b) duplex grain, (C) fine grain. 
Samples were cut from the rim of disks with different grains sizes and given the ASM $5596 \mathrm{C}$ heat treatment, i.e. $950^{\circ} \mathrm{C} / 1 \mathrm{~h} / \mathrm{AC}+720^{\circ} \mathrm{C} / 8 \mathrm{~h} / \mathrm{FC}$

$50^{\circ} \mathrm{C} / \mathrm{h} \rightarrow 620^{\circ} \mathrm{C} / 8 \mathrm{~h} / \mathrm{AC}$ Mechanical property samples were tensile tested at $650^{\circ} \mathrm{C}$, smooth and notched bar stress rupture tested at $650^{\circ} \mathrm{C} / 686 \mathrm{MPa}$, cyclic stress rupture tested at $650^{\circ} \mathrm{C} / 686 \mathrm{MPa}$ with different holding times or LCF tested.

Structural characterization techniques included optical, SEM and TEM microscopy, fractography, Auger analysis and X-ray analysis of extracted residues.

\section{EXPERIMENTAL RESULTS}

Mechanical Properties

In order to study systematically the grain size and $\mathrm{Mg}$ effects on mechanical properties, different grain size disks of $\mathrm{Mg}$ free (718) and $\mathrm{Mg}$ containing (718M) alloys were made. Different forging procedures were used which produced various amounts of recrystallized and unrecrystalized grains especially in the mixed grain disks. After the ASM $5596^{\circ} \mathrm{C}$ heat treatment, grain sizes of the experimental disks of the two alloys varied from ASTM 3 to ASTM 10. The mix ed grain disks of alloy 718 and $718 \mathrm{M}$ displayed a necklace structure of ASTM 7-8 fine grains surrounded by ASTM 3-4 coarse grains (see Fig. 1).

Results of $650^{\circ} \mathrm{C}$ tensile tests on all grain size disks showed that $\mathrm{Mg}$ can greatly increase ductility but had little effect on ultimate strength, which is only increased by grain refining (see Fig. 2).

Similar to that seen in tensile tests, $\mathrm{Mg}$ can remarkably increase the $650^{\circ} \mathrm{C}$ stress rupture ductility as shown in Fig. 3. It should be noted that $\mathrm{Mg}$ not only can increase smooth $S / R$ life but also increase notch $S / R$ life considerably even in mixed grain samples of alloy $718 \mathrm{M}$. Smooth bar S/R tests of mixed grain samples from $\mathrm{Mg}$ free alloy 718 disk show only $109 \mathrm{hrs} / 4.7 \%$ elongation, but $176 \mathrm{hrs} / 20.2 \%$ elongation from Mg containing $718 \mathrm{M}$ disk. Smooth bar S/R life decreases where notch $\mathrm{S} / \mathrm{R}$ life increases with finer grain size in $\mathrm{Mg}$ free alloy 718 . It is clear from Fig. 2 that $\mathrm{Mg}$ free alloy 718 will be susceptible to $\mathrm{S} / \mathrm{R}$ notch sensitivity when grain size is coarser than ASTM 5. A positive advantage of alloy $718 \mathrm{M}$ is that $\mathrm{Mg}$ increases the notch $\mathrm{S} / \mathrm{R}$ life remarkably; consequently, $\mathrm{Mg}$ containing alloy $718 \mathrm{M}$ is not susceptible to $S / R$ notch sensitivity even at coarse grain and mixed grain conditions. This should be of great benefit for forging of disks.

High temperature LCF or cyclic stress rupture characters are the most important mechanical properties for gas turbine disk application. A study of the grain size and $\mathrm{Mg}$ effects on cyclic stress rupture life with different holding times $(5,180$, $1800 \mathrm{sec}$ ) at maximum stress of $686 \mathrm{MPa} / 650^{\circ} \mathrm{C}$ showed that $\mathrm{Mg}$ really improved cyclic stress rupture (namely stress controlled LCF with dwelling time) properties at fatigue and creep interaction conditions, representative of disk service conditions.

\section{Microstructure Analyses}

Microchemical phase analysis results show that the amount of main strengthening phase of $\gamma^{\prime \prime}$ and $\gamma^{\prime}$ phases is not affected by $\mathrm{Mg}$ addition or grain size in alloy 718 and $718 \mathrm{M}$ as shown in Fig. 5 . $\mathrm{Mg}$ free alloy 718 or $\mathrm{Mg}$ containing alloy $718 \mathrm{M}$ both contains approximately $14 \% \gamma^{\prime}+\gamma^{\prime \prime}$ strengthening phase, independent of grain size. However, $\delta-\mathrm{Ni}_{3} \mathrm{Nb}$ phase precipitated at grain boundaries increases with grain refinement and amount of $\mathrm{Mg}$. Consequently, the amount of $\delta-\mathrm{Ni}_{3} \mathrm{Nb}$ is much higher in fine grain alloy $718 \mathrm{M}$ as compared to $\mathrm{Mg}$ free alloy 718 . 


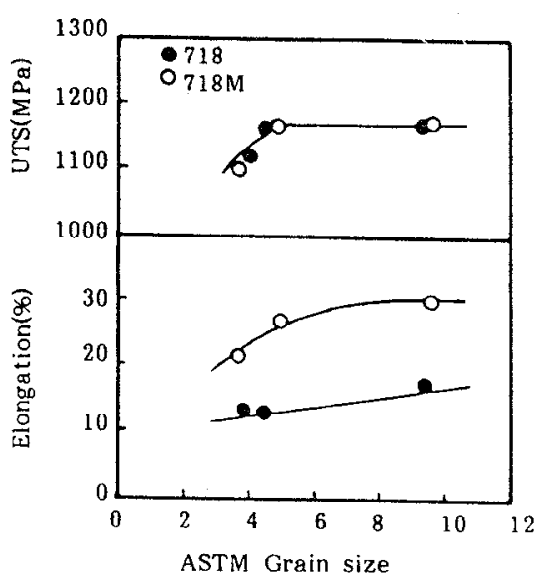

Fig. 2. Grain size and $\mathrm{Mg}$ effect on $650^{\circ} \mathrm{C}$ tensile properties.

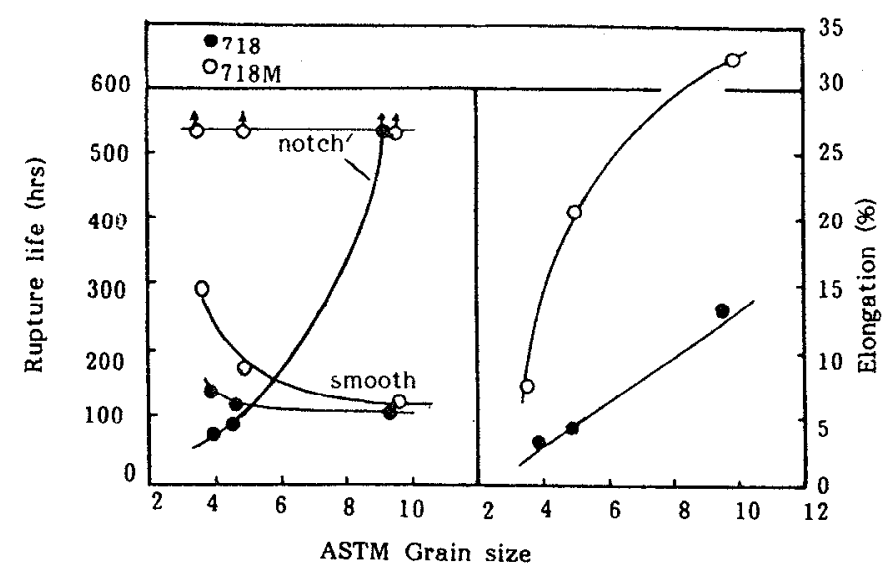

Fig. 3. Grain size and $\mathrm{Mg}$ effect on stress rupture life and elongation at $650^{\circ}$ C, $686 \mathrm{MPa}$.

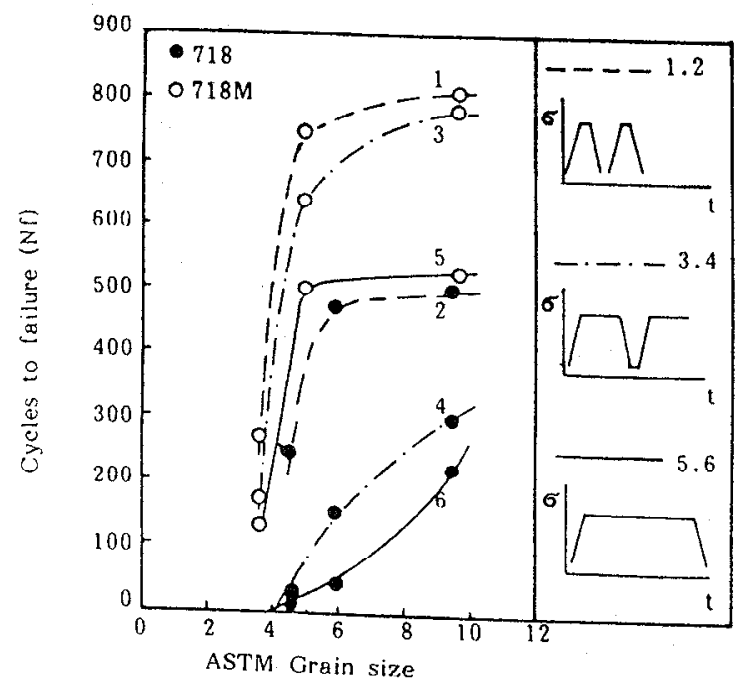

Fig. 4. Grain size and Mg effect on cyclic stress rupture 1 ife with different holding times at maximum stress of $686 \mathrm{MPa}$, $650^{\circ} \mathrm{C}$.

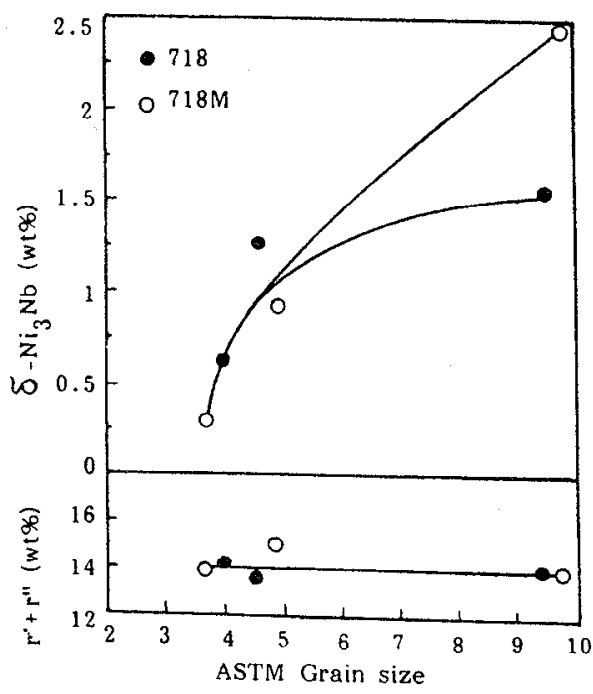

Fig. 5. Grain size and $\mathrm{Mg}$ effect on the amount of $r^{\prime \prime}$ and $\sigma-\mathrm{Ni}_{3} \mathrm{Nb}$.

$1,2-5 \mathrm{sec}, 3,4-180 \mathrm{sec}, 5,6-1800 \mathrm{sec}$

$\mathrm{Mg}$ addition to alloy 718 increases not only $\delta-\mathrm{Ni}_{3} \mathrm{Nb}$ amount but also changes its morphology from plate-like form to globular and discrete form as shown in Fig. 7 (A and D). Quantitative analysis on the amount of grain boundary $\delta-\mathrm{Ni}_{3} \mathrm{Nb}$ shows that concentration coefficient of $\delta-\mathrm{Ni}_{3} \mathrm{Nb}$ at grain boundaries (number of $\delta$ particles/wt $\% \delta$ in certain area) increases with grain refinement because of the increment of total grain boundaries. $\mathrm{Mg}$ addition can raise $\delta-\mathrm{Ni}_{3} \mathrm{Nb}$ concentration coefficient at grain boundaries to a higher level in alloy $718 \mathrm{M}$ than in alloy 718 (see Fig. 6). Thus, much smaller and more particles of $\delta-\mathrm{Ni}_{3} \mathrm{Nb}$ phase appear in $\mathrm{Mg}$ containing alloy $718 \mathrm{M}$ with fine grain structure. 


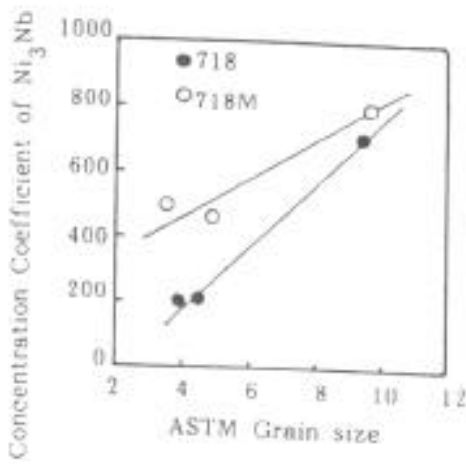

Fig. 6. Grain size and Mg effect on concentration coefficient of $\mathrm{N}$ $\mathrm{Ni}_{3} \mathrm{Nb}$ at grain boundaries.

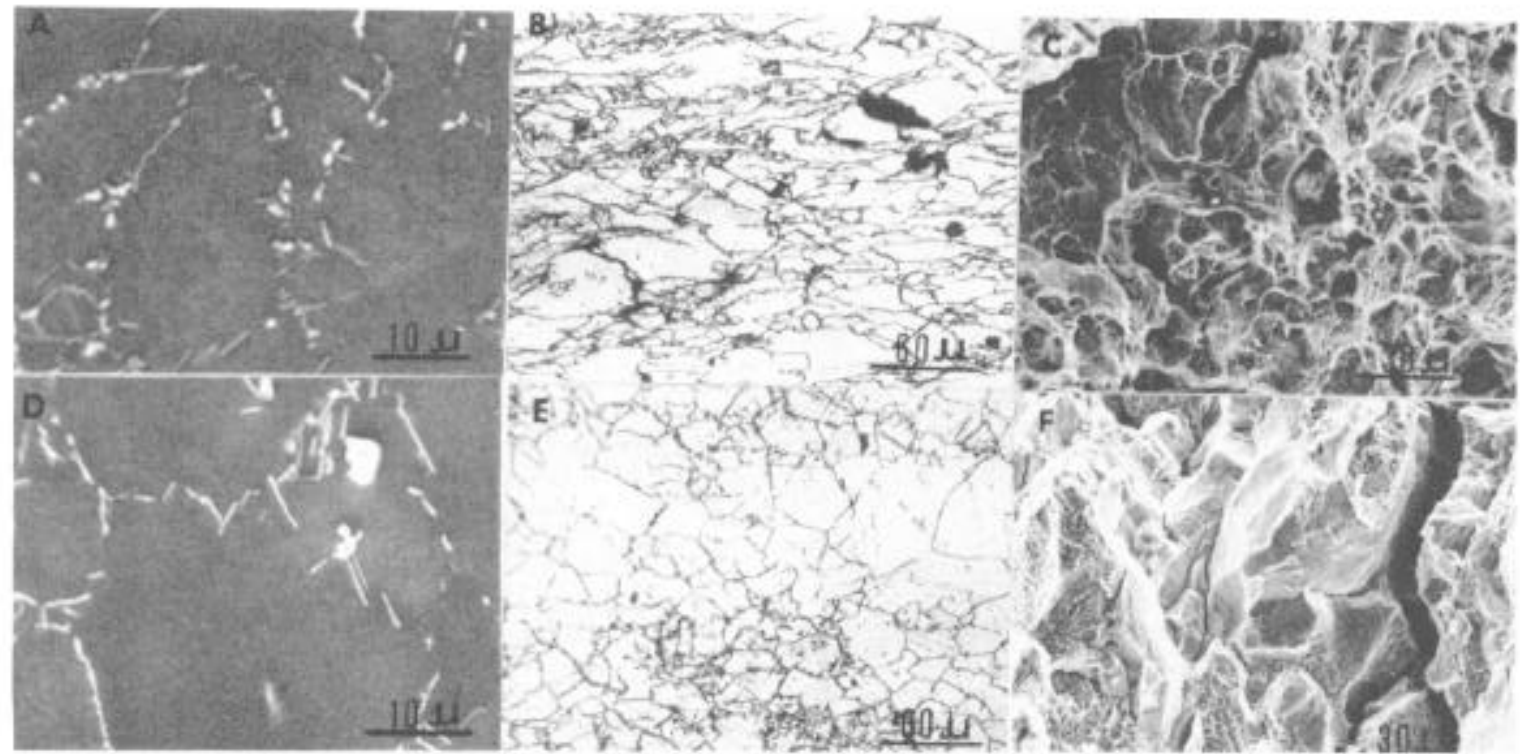

Fig. 7. $\mathrm{Mg}$ effect on grain boundary behavior of alloy $718 \mathrm{M}(\mathrm{A}, \mathrm{B}, \mathrm{C})$ and 718 $(\mathrm{D}, \mathrm{E}, \mathrm{F})$. $\mathrm{A}, \mathrm{D}$ - grain boundary $\mathrm{Ni}_{3} \mathrm{Nb}$ behavior,

$B, E$ - grain boundary crack behavior,

C, F - intergranular fracture behavior at $650^{\circ} \mathrm{C}, 686 \mathrm{MPa}$.

\section{Fractography Observation}

Optical microscopy observation on longitudinal sections of stress rupture samples shows extended elongated grain structure of $\mathrm{Mg}$ containing alloy $718 \mathrm{M}$ with grain boundary cavities because of high stress rupture ductility (see Fig. 7). In contrast, very small elongation of grains and scarce grain boundary cracks appear in $\mathrm{Mg}$ free alloy 718 (see Fig. $7 \mathrm{E}$ )

SEM fractographic study of the various grain size stress rupture samples stiows that when $\mathrm{Mg}$ is present the coarse and mixed grain samples have many more dimples on the intergranular fracture surfaces than in $\mathrm{Mg}$ free samples (compare Fig. $7 \mathrm{C}$ and $\mathrm{F}$ ). As the grain size decreases, the intergranular fracture mode changes into a partially transgranular mode. The change from intergranular to transgranular fracture occurs in the mixed grain stress rupture samples of $\mathrm{Mg}$ containing alloy $718 \mathrm{M}$ while in $\mathrm{Mg}$ free alloy 718 transgranular fracture is never totally achieved even in fine grain stress rupture samples. 
Semi-quantitative Auger analysis on intergranular fracture surface of $\mathbf{M g}$ containing alloy $718 \mathrm{M}$ samples shows the profile of $\mathrm{Mg}$ content distribution at the grain boundary regions. It can be seen from Fig. 8 that the concentration of $\mathrm{Mg}$ at grain boundaries characterizes an equilibrium segregation and $\mathrm{Mg}$ has been further concentrated at grain boundaries during long time stress aging time, i.e. $\mathrm{Mg}$ content at grain boundaries increases after $526 \mathrm{hrs}$ stress aging at $650^{\circ} \mathrm{C} / 686 \mathrm{MPa}$. After AMS $5596 \mathrm{C}$ heat treatment and $526 \mathrm{hrs}$ stress aging conditions, the concentration of $\mathrm{Mg}$ decreases gradually away from the grain boundary. The gradual change of $\mathrm{Mg}_{\mathrm{g}}$ content in the region of grain boundary shows that $M g$ does not exist in grain boundary phases; otherwise, the $\mathrm{Mg}$ content would sharply change across the grain boundary.

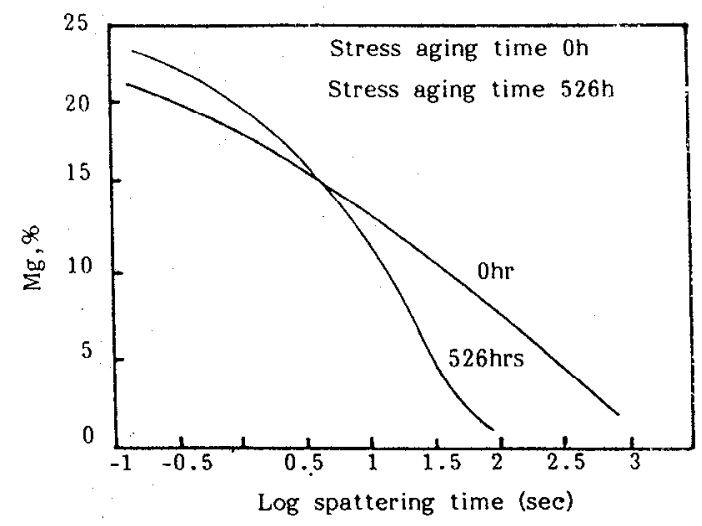

Fig. 8. Grain boundary segregation behavior of $\mathrm{Mg}$ in alloy $718 \mathrm{M}$ before and after stress aging at $650^{\circ} \mathrm{C}, 686 \mathrm{MPa}$.

$\underline{\text { Segregation Effect }}$

Because the degree of $\mathrm{Nb}$ segregation remaining after any conversion process results in non-uniform grain sizes and affects the $\delta-\mathrm{Ni}_{3} \mathrm{Nb}$ solvus temperature, the heat treated samples were given the "TAG" heat treatment [7] to detect residual segregation of $\mathrm{Nb}$. It was found that the $\mathrm{Mg}$ containing alloy $718 \mathrm{M}$ samples appear to have less segregation than $\mathrm{Mg}$ free alloy 718 .

\section{DISCUSSION}

The great advantage of adding $\mathrm{Mg}$ to alloy 718 is that $\mathrm{Mg}$ can greatly increase $650^{\circ} \mathrm{C}$ tensile and stress-rupture ductility and also increase smooth and notch stress-rupture lives remarkably. $\mathrm{Mg}$ containing alloy $718 \mathrm{M}$ is free from stressrupture notch sensitivity, which is important for material used for disk application. In addition, another benefit of $\mathrm{Mg}$ addition in alloy 718 is that $\mathrm{Mg}$ improves creep and fatigue interaction properties (LCF or cycle stress-rupture), so necessary for turbine disk applications.

The diffusion to and segregation of $\mathrm{Mg}$ at grain boundaries changes grain boundary behavior. Magnesium addition can change grain boundary precipitation of $\delta-\mathrm{Ni}_{13} \mathrm{Nb}$ from continuous plate-like form to discrete globular shapes, and retards intergranular crack growth as schematically shown in Fig. 9. This grain boundary precipitation behavior was also confirmed in nickel-base [5] and iron-base superalloys [8]. The amount of $\delta \mathrm{Ni}_{3} \mathrm{Nb}$ precipitation at the grain boundaries depends on grain size, amount of $\mathrm{Mg}$, and heat treatment. 
Because $\mathrm{Mg}$ is concentrated at the grain boundaries, $\mathrm{Mg}$ cannot severely affect precipitation behavior in bulk grains. As a result, the amount of strengthening phase $\left(\gamma^{\prime}+\gamma^{\prime \prime}\right)$ in grains is not affected by $\mathrm{Mg}$ addition in alloy 718 and is nearly constant $\left(\sim 14 \% \gamma^{\prime}+\gamma^{\prime \prime}\right)$ in both alloy 718 and $718 \mathrm{M}$ at all grain sizes.

Concentration of $\mathrm{Mg}$ at grain boundaries plays a strengthening role on grain boundaries. It allows more deformation in bulk grains before intergranular fracture occurs in stress-rupture tests. From the viewpoint of creep, Mg prolongs the secondary creep stage and develops a tertiary creep stage in nickel-base and iron-base superalloys [8] which should raise both stress rupture ductility and failure life. Ductile stress-rupture fracture surfaces with much more dimples should appear in $\mathrm{Mg}$ containing alloy $718 \mathrm{M}$ samples.

It appears $\mathrm{Mg}$ can reduce the $\mathrm{Nb}$ segregation in cast alloy 718 ingots which allows for material homogenity improvement during conversion practice. Detail study of $\mathrm{Mg}$ effect on segregation behavior will be discussed in other papers [9].

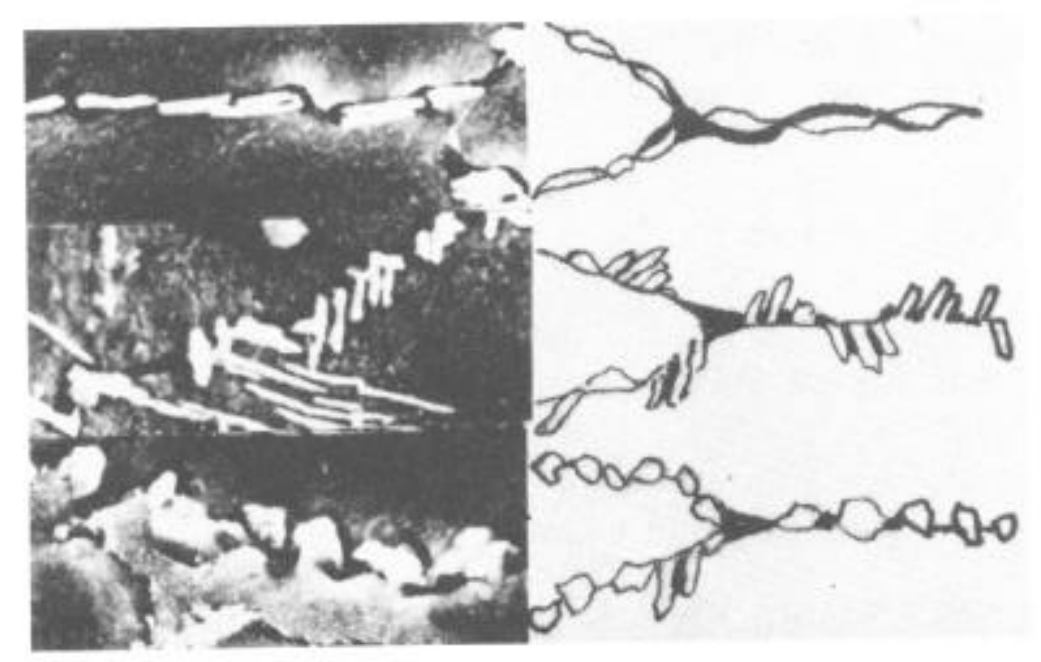

Fig. 9. Grain boundary $\sigma-\mathrm{Ni}_{3} \mathrm{Nb}$ behavior and intergranular crack propagation mode suggested.

\section{CONCLUSIONS}

1. $\mathrm{Mg}$ increases $650^{\circ} \mathrm{F}$ tensile and stress-rupture ductilities remarkably but has little effect on tensile strength; however, the smooth and notch stress-rupture lives both increase considerably and $\mathrm{Mg}$ containing alloy $718 \mathrm{M}$ is free of stressrupture notch sensitivity at any grain size.

2. $\mathrm{Mg}$ improves $650^{\circ} \mathrm{C}$ creep and fatigue interaction properties (LCF or cyclic stress-rupture) at any grain size.

3. $\mathrm{Mg}$ does not appear to have effect on the wt.\% of strengthening phase $\left(\gamma^{\prime}+\gamma^{\prime}\right)$. However, the wt. $\%$ of $\delta-\mathrm{Ni}_{3} \mathrm{Nb}$ is much greater in fine grain alloy $718 \mathrm{M}$ indicating that $\mathrm{Mg}$ affects the precipitation of $\delta-\mathrm{Ni}_{3} \mathrm{Nb}$ at grain boundaries.

4. Mg plays a role of equilibrium segregation at grain boundaries and changes grain boundary $\delta-\mathrm{Ni}_{3} \mathrm{Nb}$ morphology from continuous plate-like form to discrete globular shapes, producing a retardation effect on intergranular fracture which simultaneously increases stress-rupture ductility and prolongs failure life. 
5. Mg can produce ductile stress rupture fracture and hasten the change from intergranular fracture mode into partially transgranular mode.

6. $\mathrm{Mg}$ may appear to be beneficial to improve $\mathrm{Nb}$ segregation in alloy 718 .

\section{ACKNOWLEDGEMENTS}

The authors are grateful to the Daye Steel Works for melting and forging alloys in plant and conducting time consuming stress-rupture tests. Special thanks go to Shimu Zhou and Ziufeng Cheng for experiment arrangement and Yingzhi Zhu for conducting microchemical analyses of samples in the R\&D of Daye Steel Works.

\section{REFERENCES}

1. W. H. Couts, Jr., et al., "Effect of Magnesium as an Alloying Element in Inconel 718," (Report AEML-TR-7s-76, 1971).

2. D. R. Muzyka, et al., "Process for Making Nickel Base Precipitation Hardenable Alloys," (U.S. Patent 3575734, April 20, 1971.

3. J. M. Moyer, "Extra Low Carbon Alloy 718," in Proceedings of Superalloys, 1984, M. Gell et al., eds. AIME (1984) 443-454.

4. Z. Xr and P. Ma, eds., The effect and Control of Trace Elements in Superalloys, (Beijing, Metallurgical Press, In Chinese, 1987.

5. G. Chen, D. Wang, Z. Xu and X. Xie, et al., "The Role of Small Amounts of Magnesium in Nickel-Base and Iron-Nickel-Base Superalloys after High Temperature Long Time Exposures," in Proceedings of Superalloys 1984, M. Gell et al., eds. AIME (1984) 611-620.

6. Z. Xu, X. Xie and G. Chen, et al., "Mg Microalloyed $\mathrm{CrH}\left(6^{\circ}\right)^{\text {" in Proceedings }}$ of the Effect and Control of Trace Elements in Superalloys, Z. Xu and.P. Ma, eds., Metallurgical Press, Beijing (1987) 147-153.

7. J. A. Corrado, W. H. Couts, Jr. and J. F. Radavich, "A Microstructural Test for Chemical Homogeneity in Inconel 718 Billet," TMS Technical Paper No. A86-34, (1986).

8. X. Xie, et al., "Effect of Small Amount of Magnesium on High Temperature LCF Behavior in Iron-Base and Nickel-Base Superalloys," in Proceedings of Low Cycle Fatigue and ElastorPlastic Behavior of Materials, K. T. Rie, ed., Elsevier Applied Science (1987) 719-723.

9. X. Xie and Z. Xu, et al., "Magnesium Effect on Segregation Behavior in Alloy 718 ," to be published. 